\title{
Cultural Consumption as a Trait of a Sustainable Lifestyle: Evidence from the European Union
}

\author{
By Călin Vegheș ${ }^{1}$
}

\begin{abstract}
At a first sight, the consumption of cultural goods, services, events, and activities is expected to improve significantly the individual's wellbeing and quality of life and, reciprocally, overall good quality of life should stimulate the cultural access, participation, and consumption. First evidence that things could stay differently comes from the European Union where, paradoxically, the relatively high overall quality of life does not correspond to a similar level of cultural access, participation, and consumption. Are there significant connections between the consumption of cultural goods, services, events, and activities and the overall quality of life? Does cultural consumption contribute to a sound improvement of the individual's quality of life? May cultural consumption be defined as a trait of a sustainable lifestyle? These are the main questions this paper aims to answer based on the secondary data regarding cultural access, participation, and consumption, and quality of life at the level of the European Union.
\end{abstract}

Keywords: Cultural consumption, quality of life, sustainable development

\section{Introduction}

"Happy People Read and Drink Coffee" is the title of the successful book published, in 2013, by Agnès Martin-Lugand, and followed, just two years later, by the sequel "Don't Worry, Life Is Easy". Putting aside the narratives, the common connotation of these titles may inspire anyone of us to make and explore a potential connection, at a first sight, between the books, coffee, and life, probably under the form of an interesting book, good coffee, and comfortable life. At a more thorough assessment, it could be, in fact, about a relationship between cultural participation, in a conducive environment, resulting in a better overall experience of life. Hence, the idea of this exploratory approach measuring the associations between cultural participation (and consumption) and the overall quality of life.

We are living in consumer societies defined by Szejnwald Brown and Vergragt (2016) as complex systems of technology, culture, institutions, markets, and dominant business models driven by the ideology of neoliberalism and infinite growth and evolving through sophisticated exploitation of the fundamental human quest for a meaningful life and wellbeing yet with a high ecological cost. According to the UN System Task Team on the Post-2015 UN Development Agenda (2012), culture can be a powerful driver for the sustainable development due to the contribution to the economy and poverty alleviation, the range of non-monetized benefits (greater social inclusiveness and rootedness, resilience, innovation, creativity and entrepreneurship for individuals and communities, the use of local resources, skills, and knowledge), and the influence of the cultural factors over the lifestyles, individual behavior, consumption patterns, values related to 
environmental stewardship, and interaction with the natural environment. Culture tends to become the fourth pillar of sustainable development and culturally sustainable development adequately encompasses all the meanings of culture and all its complex interactions with the social, economic, and environmental dimensions of human life (Sabatini, 2019).

As Barrère (2016) states, culture matters, particularly that which has stood the test of time becoming heritage and that which has spillover effects - cultural goods, cultural commons, and cultural heritages impacting economic choices and performances, as well as the quality of social life. Leisure and cultural consumption are seen today as key components in a person's or a nation's quality of life (Coulangeon, 2015). Still, as Axon (2017) has noticed there is a limited number of studies exploring understandings of sustainable lifestyles amongst the public and considerations of how individuals are attempting to live more sustainably alongside indications as to what works to facilitate and what prevents it, sustainable lifestyles being practiced in various social and spatial contexts of work, leisure, travel, and community-related areas. According to the Task Force for Sustainable Lifestyles (2010), living in sustainable style involves rethinking the ways of living, buying and organizing the everyday life; also, altering the ways of socializing, exchanging, sharing, educating and building identities; and transforming societies and living in harmony with the natural environment. The sustainable lifestyles are widely recognized but oftencontested descriptions of how citizens or consumers conduct conscious or habitual practices that benefit the local or global environment, drawing more on the social than the individual as a frame of reference (Barr, 2015).

Van Hek and Kraaykamp (2013) have measured the associations between cultural consumption and the individual and contextual (country-level) characteristics and observed that highbrow cultural consumption is affected by a nation's wealth, social mobility level, and level of cultural funding and supply, and advanced an explanation according to which specific country characteristics related to governmental policies and economic, cultural and historical development could increase highbrow cultural consumption among all population's layers. Anticipatedly, Aoyama (2007) suggested that rise of the cultural industries will be facilitated not by the material status or consumers' education but by growing popularity of leisure and entertainment activities and capacities of these industries to provide an experience, a new and growing source of value in the economy, in commodified and uncommodified forms.

\section{Methodological Notes}

The scope of the research was to explore the links between the cultural participation and the quality of life of the European Union consumers to assess if the cultural participation contributes to the improvement of the quality of life, and, consequently, if the cultural consumption can be seen as a trait of a sustainable lifestyle.

Cultural participation has been assessed using two composites variables determined at the level of each European Union country based on the frequency of conducting and/or participating in different cultural activities measured at the levels of the entire market, respectively of the segment of effective consumers. For this research, the cultural activities have been considered as they are defined in the Special Eurobarometer 399 on Cultural 
Access and Participation (2013): seeing the ballet, dance or opera performances; going to the cinema; going to the theatre; going to the concerts; visiting public libraries; visiting historical monuments or sites (palaces, castles, churches, gardens, etc.); visiting museum or galleries; watching or listening cultural programs on TV or radio, and reading books. The quality of life has been assessed taking into consideration the broader and multidimensional concept developed by Mercy et al. (2015) along eight dimensions related to people's capabilities to pursue their self-defined well-being, according to their values and priorities, respectively material living conditions; productive or main activity (covering employment); health; education; leisure and social interactions; economic and physical safety; governance and basic rights; natural and living environment, together with the 'overall experience of life' referring to the personal perception of the quality of life (life satisfaction, affects, the meaning of life).

The research objectives of this exploratory approach were to measure and assess the relationships between the:

(1) cultural participation and overall quality of life of the European consumers;

(2) cultural participation and dimensions of the quality of life: material living conditions; productive or main activity; health; education; social relations and leisure; economic and physical safety; governance and basic rights; natural and living environment;

(3) cultural consumption and sustainability-related aspects of the consumers' lifestyle.

The associated research hypotheses of this exploratory approach assumed that:

(1) increased cultural participation is significantly associated with overall improved quality of life of the European consumers;

(2) increased cultural participation is significantly associated with better or improved material living conditions, conditions of productive or other main activities, health status, attained levels of education, social relations and leisure, levels of economic and physical safety, governance and basic rights, and natural and living environment;

(3) increased cultural consumption may be seen as a trait of a sustainable lifestyle of the European consumer.

To achieve the research objectives and to verify their associated assumptions, the following set of research variables and sub-variables was considered:

1. Cultural access and participation of European consumers:

1.1. CULT_MK: average frequency of participation in the cultural activities (determined at the level of the EU, respectively national cultural markets);

1.2. CULT_EC: average frequency of participation in the cultural activities (determined at the national and EU levels, for the segments of the effective cultural consumers).

2. Quality of life of EU consumers:

2.1. LIFESAT: self-evaluation of the individual's satisfaction with his/her life, understood as comprising all areas of a person's existence, taken as a whole and expressed on a scale from 0 to 10 (where 0 means not at all satisfied and 10 completely satisfied);

2.2. LIFEMEA: self-evaluation of the individual's satisfaction with his/her value and purpose of life, important life goals, and for some, spirituality, and expressed on a scale from 0 to 10 (where 0 means not at all satisfied and 10 completely satisfied);

2.3. LIFEHAP: self-evaluation of the individual's degree of happiness based on the people's day-to-day feelings and moods in terms of how much from the past four weeks 
before the interview they were happy, and expressed on a scale from 0 to 3 (where 0 means not of the time and 3 all of the time).

3. Material living conditions:

3.1. MNEINC (Median Net Equalized Income): income from market sources and cash benefits after deduction of direct taxes and regular inter-household cash transfers, adjusted for household size and composition, and available to the household for spending or saving (expressed in euro);

3.2. FINSAT: level of satisfaction with the financial situation expressed on a scale from 0 to 10 (where 0 means not at all satisfied and 10 completely satisfied);

3.3. OVCROW: the overcrowding rate is defined as the share of the population living in an overcrowded household computed by comparing the total number of rooms available with this minimum number of rooms needed (expressed as a percentage);

3.4. ACCSAT: level of satisfaction with the accommodation expressed on a scale from 0 to 10 (where 0 means not at all satisfied and 10 completely satisfied).

4. Productive or main activity

4.1. EMPLOY: the employment rate expressed as the number of employed people as a proportion of the population aged 15-64 (expressed as a percentage);

4.2. JOBSAT: level of satisfaction with the job expressed on a scale from 0 to 10 (where 0 means not at all satisfied and 10 completely satisfied);

4.3. WORKHR: the average number of weekly hours spent at work (number of hours);

4.4. TIMESAT: level of satisfaction with the time use expressed on a scale from 0 to 10 (where 0 means not at all satisfied and 10 completely satisfied);

4.5. COMMSAT: level of satisfaction with the commuting time expressed on a scale from 0 to 10 (where 0 means not at all satisfied and 10 completely satisfied).

5. Health

5.1. LIFEXB: the mean number of years a newborn child can expect to live if subjected throughout his or her life to the current mortality conditions (number of years);

5.2. SELFHE: the self-perceived health in general status as good or very good as a result of an individual's assessment based on the different dimensions of health (such as physical, social, and emotional function and biomedical signs and symptoms; expressed as a percentage).

6. Education

6.1. EDUAT23: the educational attainment of the population the proportion of the population reaching the secondary and tertiary level of education (expressed as a percentage).

6.2. NETSKIL: self-assessed level of basic internet skills by individuals in terms of their abilities to carry out at least one from a set of six related activities (percentage of individuals aged 16-74).

7. Social relations and leisure

7.1. GOVSRC: Government spending on recreational and cultural activities in total public expenditures (expressed as a percentage in the Gross Domestic Product).

7.2. HOUSRC: Household spending on recreational and cultural activities (in euro);

7.3. RELSAT: Satisfaction with personal relationships expressed on a scale from 0 to 10 (where 0 means not at all satisfied and 10 completely satisfied).

8. Economic and physical safety 
8.1. INAFIN: percentage of the population unable to face the unexpected required expense and pay through its resources.

8.2. FEELSF: self-perceived level of safety in terms of how safe they felt when walking alone in their area at night (expressed as a percentage).

9. Governance and basic rights

9.1. TRUSTO: the level of trust in other persons expressed on a scale from 0 to 10 (where 0 means 'You do not trust any other person' and 10 'Most people can be trusted').

9.2. TRUSTL: the level of trust in the legal system expressed on a scale from 0 to 10 (where 0 means 'No trust at all' and 10 'Complete trust').

9.3. TRUSTP: the level of trust in the political system expressed on a scale from 0 to 10 (where 0 means 'No trust at all' and 10 'Complete trust').

10. Natural and living environment

10.1. LENSAT: the level of satisfaction with the living environment expressed on a scale from 0 to 10 (where 0 means not at all satisfied and 10 completely satisfied);

10.2. GRESAT: the level of satisfaction with the recreational and green areas expressed on a scale from 0 to 10 (where 0 means not at all satisfied and 10 completely satisfied).

The assessment of the relationships between the cultural participation and the quality of life has been conducted considering two levels: (1) individual, described by the EU consumers' perceptions and self-assessments of the different dimensions of the quality of life expressed by the following 17 sub-variables - FINSAT, ACCSAT, JOBSAT, TIMESAT, COMMSAT, SELFHE, NETSKIL, HOUSRC, RELSAT, INAFIN, FEELSF, TRUSTO, TRUSTL, TRUSTP, LENSAT, and GRESAT; (2) contextual, described by the social and economic indicators characterizing the entire market and influencing the individual cultural participation and consumption expressed by the following nine sub-variables - MNEINC, OVCROW, EMPLOY, WORKHR, LIFEXB, EDUAT23, GOVSRC, GDPc (Gross Domestic Product per capita), and HDI (Human Development Index).

Data about the above-mentioned variables have been collected from the European Commission's Special Eurobarometer on Cultural Access and Participation (2013) - and processed using JASP (an open-source project supported by the University of Amsterdam). Pearson correlation coefficients have been determined and a correlation matrix has been established to assess the associations between the investigated variables.

\section{Main Findings}

The European consumer participated in a relatively modest amount (16) of cultural activities, as an annual average, including listening and/or watching four radio and/or television cultural programs ( $72 \%$ of the European cultural consumers conducting at least once this activity), reading three or four books (68\% at least one), going two times to the cinema (52\% at least once), visiting two monuments and historical sites (52\% at least one), visiting once or twice public libraries (31\% at least one), visiting one museum (37\% at least one), going to one concert (35\% at least one), seeing one theatre performance (28\% at least one) and possibly seeing one ballet, dance or opera performance (18\% at least one). As the data of the Special Eurobarometer 399 (2013) reveal, the lack of interest and the lack of time are the main barriers for practically all the 
cultural activities.

There were statistically significant differences between the 27 cultural markets of the European Union members in terms of cultural participation $\left(\chi^{2}\right.$ calc $=41.27, \chi^{2}$ theor $=38.89$, $n=0.05)$ : Sweden (with an average annual frequency of 28.30 activities), Denmark (24.00), and the Netherlands (23.22) are far above while Portugal (8.33), Greece (8.72), Cyprus (9.64), Romania (9.73), Hungary (9.83), Poland (11.37), Italy (11.49), and Bulgaria (11.72) are far below the European average. Considering the social, economic, and environmental differences between the Member States, the distances in terms of cultural participation are not as surprising. These variations suggest the existence of potential associations between the levels of cultural participation, socio-economic development, and quality of life and well-being within the European Union.

A higher frequency of participation in cultural activities is associated with a better quality of life and increased consumption of cultural goods, services, events, and activities tends to explain $23.42 \%$ of the overall quality of life of the European consumer.

Table 1. Correlation matrix of the cultural participation and the dimensions of the quality of life of the European consumers

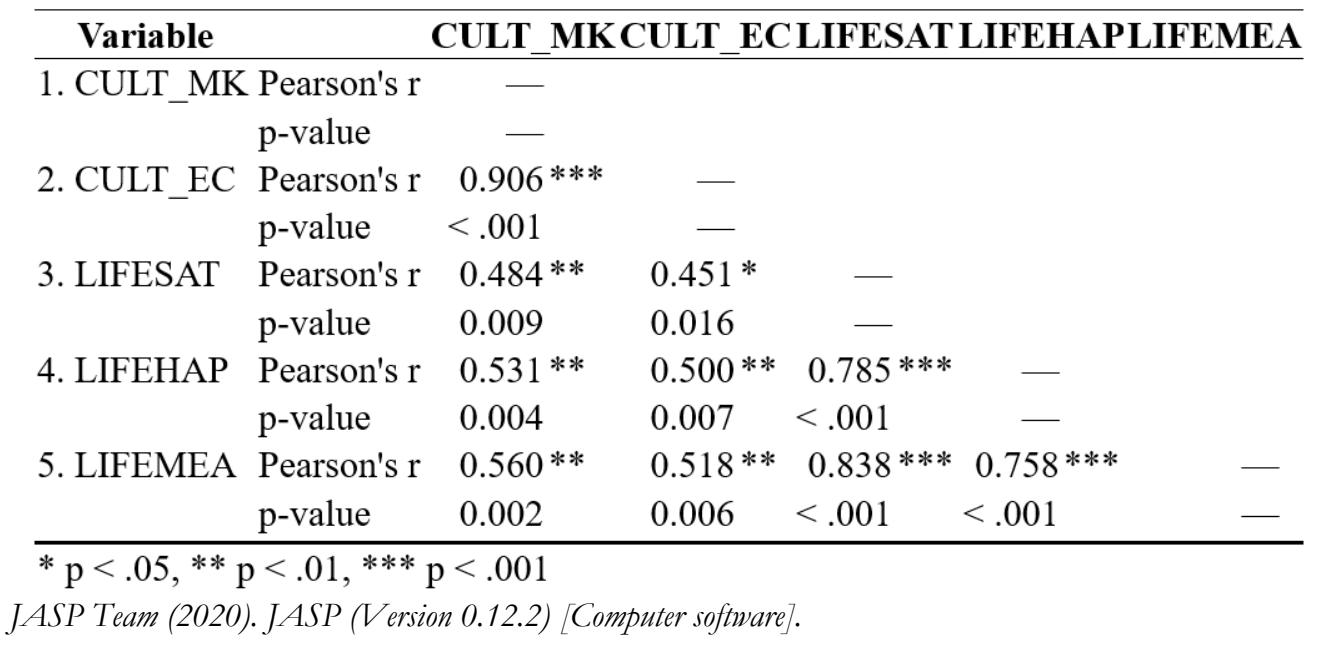

There are cultural activities contributing more and associating significantly with a better quality of life: seeing movies at the cinema $(r=0.602, \mathrm{p}<0.001)$, reading books $(\mathrm{r}=0.497$, $\mathrm{p}<0.01)$, visiting historical monuments and sites $(\mathrm{r}=0.487, \mathrm{p}<0.05)$, visiting public libraries $(\mathrm{r}=0.485, \mathrm{p}<0.05)$, and visiting museums and galleries $(\mathrm{r}=0.470, \mathrm{p}<0.05)$. All these cultural activities can be characterized as convenient - in financial terms, accessible - in intellectual terms, useful - in professional terms, socially facilitating, adequate for spending spare time, and/or holiday - in personal terms. The European consumers tend to participate and consume culture in a somewhat practical way timely adapted to their daily life needs.

Less contributing and not significantly associated to the improvement of the quality of life are watching and/or listening cultural programs on radio and/or TV ( $\mathrm{r}=0.144)$, going to the theatres $(r=0.338)$, seeing ballet, dance and opera performances $(r=0.369)$, and going to the concerts $(\mathrm{r}=0.376)$. Surprises the less significant impact of going to the theatre over 
the quality of life of the European consumer as this appears as one of the most common ways of consuming culture. Also, the European consumer tends to listen to the radio or watch television without searching specifically for cultural programs or follows cultural programs without being aware that they are consuming radio and/or television broadcasted cultural programs. Less significant contributions of the ballet, dance, and opera, respectively concerts are not surprising as they tend to be associated with the highbrow culture, one with a rather low or very low frequency of participation.

Table 2. Correlation matrix of the cultural consumption and the individual factors related to the quality of life of the European consumers

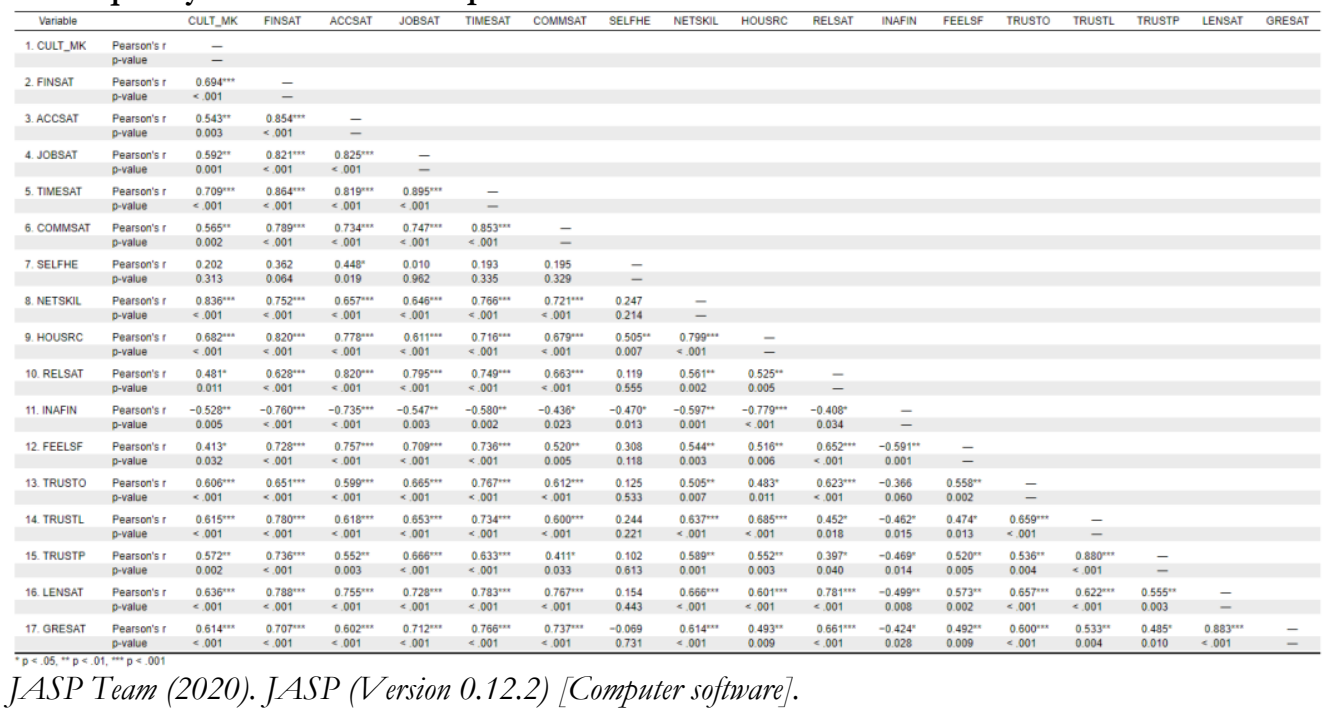

From the 16 individual factors considered, the only one did not significantly associate with cultural participation: self-perceived health status seems to not impact the frequency of participation of the European consumers in cultural activities. All others associate and influence significantly the consumption of cultural goods, services, events, and activities. Considering the levels of statistical significance $(\mathrm{p}<0.001 ; \mathrm{p}<0.01 ; \mathrm{p}<0.05)$, they can be grouped into three categories in terms of the intensity of influence exerted.

The extent to which the European consumer can use the internet to search for, communicate about, buy or experience cultural goods, services, events, and activities determines up to $70 \%$ of the frequency of cultural participation. This confirms the penetration of the internet in the cultural markets and provides a strong basis to consider it as an indispensable support for both the cultural consumers and cultural organizations. Increasing commodification in the cultural market asks cultural organizations to employ the internet not only to communicate and inform but also to enrich and diversify the cultural experiences of their audiences having as the main result the growth of cultural participation.

Satisfaction regarding the time use and, respectively the financial situation, as well as the household spending for recreation and culture, determine about 46 to $50 \%$ of the variation of the frequency of cultural participation. The cultural consumption tends to be higher 
among the individuals that manage better their time and finances finding the time and budgetary availabilities for cultural experiences (that reconfirm the lack of time and money, together with the lack of interest, as main barriers for the cultural participation).

Living in an appropriate environment facilitates, also significantly, the frequency of cultural participation, as the availability of the green areas. The access to services such as commercial and public transportation, the presence of cinema, museums, and theatres, as well as of the green and recreational spaces in the vicinity of the place where the consumers circulate creates the appropriate background and determines the participation in the cultural activities, particularly in those conducted outside the home, in a proportion of 38$40 \%$. The trust in others and the legal system contributes significantly to the creation of a favorable context for the cultural participation influencing its frequency up to $36-38 \%$. A consumer trusting those around him/her and the rule of law provided by a trustworthy legal system is more open to participating in cultural activities.

Other significant influences over the cultural participation but determining less (between 28 and $35 \%$ ) its frequency is exerted by the satisfaction regarding the current job, trust in the political system, satisfaction regarding the commuting time to the place of work, satisfaction regarding the accommodation, and the ability to face unexpected financial expenses. The European consumer tends to participate more frequently cultural activities if he or she is satisfied with the job, trusts reasonably the political system (and has fewer concerns about the politics and its influences over the daily life), commutes conveniently (having even opportunities to consume culture by reading or watching cultural programs over the internet), lives in reasonable housing conditions (having the necessary comfort to experience and enjoy indoor cultural activities), and last but not least, has the necessary financial resources to cope the stress created by the unexpected circumstances.

Finally, satisfaction with personal relationships and the feeling of safety are strongly associated with the overall quality of life and well-being of the European consumers and also exert a significant, but less determinant (between 17 and $23 \%$ ) influence over the cultural participation. An improved level of social interactions and relationships, respectively a better level of physical safety translates in more frequent participation in cultural market as the European consumer tends to experience more cultural goods, services, events, and activities in an environment in which connects more satisfactory with his or her acquaintances and feels safer in terms of the physical security-related risks. 
Table 3. Correlation matrix of the cultural consumption and the contextual factors related to the quality of life of the European consumers

\begin{tabular}{|c|c|c|c|c|c|c|c|c|c|c|c|}
\hline Variable & & CULT_MK & MNEINC & OVCROW & EMPLOY & WORKHR & LIFEXB & EDUAT 23 & GOVSRC & GDPC & HDI \\
\hline \multirow[t]{2}{*}{ 1. CULT_MK } & Pearson's r & - & & & & & & & & & \\
\hline & $\mathrm{p}$-value & - & & & & & & & & & \\
\hline \multirow[t]{2}{*}{ 2. MNEINC } & Pearson's r & $0.601^{* * \star}$ & - & & & & & & & & \\
\hline & p-value & $<.001$ & - & & & & & & & & \\
\hline \multirow[t]{2}{*}{ 3. OVCROW } & Pearson's r & $-0.465^{*}$ & $-0.769^{* * *}$ & - & & & & & & & \\
\hline & p-value & 0.014 & $<.001$ & - & & & & & & & \\
\hline \multirow[t]{2}{*}{ 4. EMPLOY } & Pearson's r & $0.766^{\mathrm{x} \times x}$ & $0.515^{* *}$ & $-0.407^{*}$ & - & & & & & & \\
\hline & p-value & $<.001$ & 0.006 & 0.035 & - & & & & & & \\
\hline \multirow[t]{2}{*}{ 5. WORKHR } & Pearson's r & $-0.672^{* \star \star \star}$ & $-0.689^{* x *}$ & $0.602^{* \star * *}$ & $-0.640^{* * * *}$ & - & & & & & \\
\hline & p-value & $<.001$ & $<.001$ & $<.001$ & $<.001$ & - & & & & & \\
\hline \multirow[t]{2}{*}{ 6. LIFEXB } & Pearson's r & 0.216 & $0.758^{* * * x}$ & $-0.798^{* * *}$ & 0.139 & $-0.451^{*}$ & - & & & & \\
\hline & p-value & 0.280 & $<.001$ & $<.001$ & 0.490 & 0.018 & - & & & & \\
\hline \multirow[t]{2}{*}{ 7. EDUAT 23} & Pearson's r & 0.316 & -0.062 & 0.325 & $0.397^{*}$ & 0.049 & $-0.505^{* *}$ & - & & & \\
\hline & p-value & 0.108 & 0.758 & 0.098 & 0.040 & 0.808 & 0.007 & - & & & \\
\hline \multirow[t]{2}{*}{ 8. GOVSRC } & Pearson's r & $0.454^{*}$ & 0.140 & -0.065 & $0.410^{*}$ & -0.178 & -0.138 & 0.341 & - & & \\
\hline & p-value & 0.017 & 0.488 & 0.747 & 0.034 & 0.375 & 0.491 & 0.082 & - & & \\
\hline \multirow[t]{2}{*}{ 9. $\mathrm{GDPC}$} & Pearson's r & $0.561^{* *}$ & $0.941^{* * * x}$ & $-0.638^{* * *}$ & $0.464^{*}$ & $-0.620^{* x *}$ & $0.626^{* 5 * x}$ & -0.002 & 0.122 & - & \\
\hline & p-value & 0.002 & $<.001$ & $<.001$ & 0.015 & $<.001$ & $<.001$ & 0.992 & 0.543 & - & \\
\hline \multirow[t]{2}{*}{ 10. HDI } & Pearson's r & $0.649^{* * *}$ & $0.830^{* * *}$ & $-0.759^{* * *}$ & $0.550^{* *}$ & $-0.748^{* * \star}$ & $0.708^{* \star * *}$ & 0.042 & 0.200 & $0.723^{* * *}$ & - \\
\hline & $p$-value & $<.001$ & $<.001$ & $<.001$ & 0.003 & $<.001$ & $<.001$ & 0.834 & 0.317 & $<.001$ & - \\
\hline
\end{tabular}

Considering the contextual factors influencing the cultural participation, the most significant impact is exerted by the work-related factors - employment rate (determining $59 \%$ of the participation), the number of the average weekly working hours (45\%), respectively the median net equalized income of the household (36\%). Having a job appears as a prerequisite of cultural participation, as the incomes obtained as salaries and equivalent revenues are the main source of financial resources used to support the consumption of cultural goods, services, events, and activities. More, having a job that supposes a lower number of working hours and leaves more spare time creates better auspices for the cultural participation as the time that became available may be allocated, at least partially, to an increased amount of cultural experiences. The higher the income of the household is, the higher the number of cultural experiences of its members are. The physical context in which the consumer experiences culture accounts for $21 \%$ in cultural participation at the European level. The overcrowding of the housing spaces influences negatively the cultural access and participation, particularly in the case of the indoor consumption, as the consumer may not have that comfortable space in which to be willing to have cultural experiences. Last but not least, the government spending on recreational services and culture facilitates significantly the cultural consumption, which raises the questions regarding the appropriate areas of the cultural market to be financially supported through public effort and the ways of putting into practice this approach (direct subsidies, financing cultural projects, etc.).

Somehow surprisingly, the associations between the cultural consumption and the level of educational attainment, respectively the life expectancy at birth are not statistically significant. An increased cultural consumption does not necessarily mean a higher level of educational attainment at the level of the market and the vice-versa. More, as the significant association with the internet skills of the consumers proves, the cultural consumption appears as a relevant factor rather at the individual than the collective one, with a corresponding impact at an individual and not at the community level. The health status 
of European consumers does not impact cultural consumption even at the contextual level. The assumption that a healthier consumer with an extended life expectancy at birth experiences cultural goods, services, events, and activities more frequently proved to be erroneous. Except for the particular situations determined by the temporary health problems or an unfavorable medical conditions, the European consumers participate in cultural markets under the limits set by other contextual factors.

Last but not least, the impact of cultural participation of the European consumers in connection to the context in which is conducted is revealed by the relationships with the Gross Domestic Product per capita and the Human Development Index. In both cases, the associations are statistically significant and express a high level of determinacy (almost 32 , respectively $42 \%$ ). The consumption of cultural goods, services, events, and activities tends to grow to have as background the favorable and positive economic and social evolutions. Reciprocally, the economy and entire society tend to develop more consistently when the cultural participation experiences a higher level.

\section{Conclusions and Limits of the Research}

The cultural participation associates significantly to the indicators describing seven out of the eight dimensions of the quality of life (respectively material living conditions, productive or main activity, education, leisure and social interactions, economic and physical safety, governance and basic rights, and natural and living environment), the exception from the rule is that of health. Also, cultural participation associates significantly with the overall satisfaction of life taken as a whole. These results sustain the idea that higher cultural participation results in a better quality of life and, viceversa, improved quality of life creates a favorable background for extended cultural participation.

In terms of the extension, the cultural participation of the European consumers may reach an upper limit represented by an annual average amount of 33 or 34 cultural activities, as this is the number of specific activities conducted by the effective consumers. This corresponds to an overall increase of $109.12 \%$ translated in listening and/or watching five or six radio and/or television cultural programs, reading five or six books, visiting four or five times public libraries, going three or four times to the cinema, visiting three or four monuments and historical sites, visiting three museums, going to two or three concerts, seeing two or three theatre performances, and possibly seeing two or three ballet, dance or opera performances. Also, this suggests that cultural markets as a whole and their segments are in the stage in which they need a mixed development, both extensive (by increasing the number of the cultural consumers) and intensive (by increasing the average number of activities conducted by each cultural consumer). What happens to the cultural participation stays in the case of the quality of life: its overall growth depends on the increase of the number of the European citizens or consumers enjoying a better quality of life and, in the same time, by the improvements of the quality of life in all its aspects.

Can cultural participation become a trait of a sustainable lifestyle? The statistically significant associations between the frequency of participating in cultural activities and the feelings of happiness, respectively meaning of life are strong proofs in this respect. The participation of European consumers in cultural activities, respectively the consumption 
of cultural goods, services, events, and activities, contributes to the overall increase of the consumers' happiness and determines it in a proportion of $27 \%$. Cultural participation enhances the presence of positive feelings and reduces the presence of the negative ones improving the overall quality of life and well-being of the European consumers. Even more important, the cultural participation helps the consumers to be well aware of, value, and understand better their purpose of life, important life goals, and, for some, may generate a spiritual significance. Having a purpose of life, setting life goals, and acting to fulfill them balancing the material and spiritual dimensions of daily life represent characteristics of a sustainable lifestyle. Thus, the impact of cultural participation over how consumers assess the meaning of their lives transforms the consumption of cultural goods, services, events, and activities in a trait of a sustainable lifestyle.

Leaving from the premise that modern European lifestyles are unsustainable, Mont and others (2014) have advanced four scenarios for sustainable lifestyles 2050: Singular Super Champions, Governing the Commons, Local Loops, and Empathetic Communities, all highlighting the need to identify, stimulate and scale-up social innovation initiatives that complement technical innovation by changing how everyday life is organized and in which we the well-being and quality of life are defined to create individual and collective identities. As promising and optimistic as they may seem, these four scenarios reserve a rather peripheral position for culture and remains to be seen if the cultural access and participation will contribute to the overall improvement of the quality of life and the consumption of cultural goods, services, events, and activities represents a trait of a sustainable lifestyle.

The results of this exploratory research should be considered under the two important limits. First, the cultural participation has been defined through a single variable frequency of conducting specific activities which, although relevant, provides just a limited measure of the extent to which the cultural consumption can be associated to the quality of life, well-being, and the sustainable lifestyle of the European consumers. Second, the list of variables employed to illustrate the quality of life represents a selection from the set of variables used by the European Commission to assess the quality of life and well-being in the European Union, both the selection and its source could making the object of further review and improvements to provide a more sound analytical background.

\section{References}

Aoyama, Y. (2007). The role of consumption and globalization in a cultural industry: The case of flamenco, Geoforum 38, 103-113.

Axon, S. (2017). "Keeping the ball rolling": Addressing the enablers of, and barriers to, sustainable lifestyles, Journal of Environmental Psychology 52, 11-25.

Barr, S. (2015). Sustainable lifestyles. In International encyclopedia of the social and behavioral sciences. Second Edition, London: Elsevier, 828-833.

Barrère, C. (2016). Cultural heritages: From official to informal. City, Culture, and Society 7, 87-94.

Coulangeon, Ph. (2015). Leisure and Cultural Consumption: The European Perspective, in James D. Wright, International Encyclopedia of the Social \& Behavioral Sciences (Second Edition), Elsevier, p. 838845. Retrieved from http://www.sciencedirect.com/science/article/pii/B9780080970868104209.

European Commission (2013). Special Eurobarometer 399 Cultural Access and Participation. Retrieved from http://ec.europa.eu/commfrontoffice/publicopinion/archives/ebs/ebs 399 en.pdf. 
Eurostat (2017). Final report of the expert group on quality of life indicators, Statistical Reports, Eurostat, Luxembourg: Publications Office of the European Union. Retrieved from https://ec.europa.eu/eurostat/documents/7870049/7960327/KS-FT-17-004-EN-N.pdf/f29171dbe1a9-4af6-9e96-730e7e11e02f.

Katz-Gerro, T. (2004). Cultural Consumption Research: Review of Methodology, Theory, and Consequence, International Review of Sociology 14 (1), 11-29.

Mercy, J.L., Litwinska, A., Dupré, D., Clarke, S., Ivan, G. A., Stewart, C., Bautier, Ph., Montaigne, F., CorselliNordblad, L, Coyette, C., Fiasse, I., Johansson, A., Peterkova, L., Strandell, H. (2015). Quality of life in Europe - facts and views, Eurostat Statistical books, Luxembourg: Publications Office of the European Union. Retrieved from https://ec.europa.eu/eurostat/documents/3217494/6856423/KS-05-14-073EN-N/742aee45-4085-4dac-9e2e-9ed7e9501f23.

Mont, O., Neuvonen, A., Lähteenoja, S. (2014). Sustainable lifestyles 2050: stakeholder visions, emerging practices and future research, Journal of Cleaner Production 63, 24-32.

Sabatini, F. (2019). Culture as fourth pillar of sustainable development: Perspectives for integration, paradigms of action, European Journal of Sustainable Development 8 (3), 31-40.

Szejnwald Brown, H., Vergragt, Ph. J. (2016). From consumerism to wellbeing: toward a cultural transition? Journal of Cleaner Production 132, 308-317.

The Task Force for Sustainable Lifestyles (2010). Sustainable Lifestyles. Retrieved from http://www.unep.fr/scp/marrakech/taskforces/pdf/SLT\%20Report.pdf.

United Nations Environment Programme - Sustainable Lifestyles, Cities and Industry Branch (UN Environment) (2016). Fostering and Communicating Sustainable Lifestyles: Principles and Emerging Practices. Retrieved from http://wedocs.unep.org/bitstream/handle/20.500.11822 $\angle 17016 /$ fostering Communicating Sust Lifestyles.pdf.

UN System Task Team on the Post-2015 UN Development Agenda (2012). Culture: a driver and an enabler of sustainable development. Thematic Think Piece. Retrieved from: https://www.un.org/millenniumgoals/pdf/Think\%20Pieces/2 culture.pdf.

Van Hek, M., Kraaykamp, G. (2013). Cultural consumption across countries: A multi-level analysis of social inequality in highbrow culture in Europe, Poetics 41, 323-341. 